\title{
Claude Reichler, La Découverte des Alpes et la question du paysage
}

\section{Mariana Perisanu}

\section{(2) OpenEdition}

10 Journals

\section{Édition électronique}

URL : https://journals.openedition.org/studifrancesi/39536

DOI : 10.4000/studifrancesi.39536

ISSN : 2427-5856

Éditeur

Rosenberg \& Sellier

\section{Édition imprimée}

Date de publication : 1 décembre 2004

Pagination : 384

ISSN : 0039-2944

\section{Référence électronique}

Mariana Perisanu, "Claude Reichler, La Découverte des Alpes et la question du paysage ", Studi Francesi [En ligne], 143 (XLVIII | II) | 2004, mis en ligne le 30 novembre 2015, consulté le 19 mai 2021. URL : http://journals.openedition.org/studifrancesi/39536; DOI : https://doi.org/10.4000/studifrancesi. 39536

Ce document a été généré automatiquement le 19 mai 2021.

\section{(c)}

Studi Francesi è distribuita con Licenza Creative Commons Attribuzione - Non commerciale - Non opere derivate 4.0 Internazionale. 


\title{
Claude Reichler, La Découverte des Alpes et la question du paysage
}

\author{
Mariana Perisanu
}

\section{RÉFÉRENCE}

CLAUDE REICHLER, La Découverte des Alpes et la question du paysage, Georg Editeur, 2002, pp.

256.

1 Accompagnant un vaste travail de collecte de documents -Le Voyage en Suisse. Anthologie des voyageurs français et européens, de la Renaissance au XX $X^{\mathrm{e}}$ siècle de Cl.Reichler et $\mathrm{R}$. Ruffieux, Laffont, 1998, ce livre raconte l'histoire du paysage alpestre depuis sa naissance dans la sensibilité européenne au XVIII ${ }^{\mathrm{e}}$ siècle jusqu'au milieu du XIX ${ }^{\mathrm{e}}$ siècle, où il façonne l'âme des hommes et l'identité des sociétés. Le professeur Reichler interprète les textes et les images en anthropologue et en historien de la culture, permettant au lecteur de retrouver le sentiment de la découverte, l'exaltation des parcours, l'amplitude du paysage absolu qui ont tant ému les voyageurs d'autrefois. Les chapitres du livre sont construits autour d'objets singuliers: un recueil de gravures, un livre de voyage, une description économique, une pratique scientifique, un problème esthétique, un thème littéraire.

2 La période 1770-1830 est jugée par l'auteur une «exploration systématique, d'une théorisation scientifique et d'une haute sensibilité esthétique.» (p. 13). Le chapitre «Le charme d'une image» évoque l'épisode de la gravure alpestre dans La Confession d'un enfant du siècle où Musset enferme comme en un triangle ses personnages torturés par le doute et l'angoisse: le paysage alpin figure le lieu de l'idylle qui n'a pas eu lieu entre Sand et lui. Mais le véritable moment mythologique qui a contribué à répandre en Europe l'attrait du voyage dans les Alpes est dû à l'auteur de la célèbre «Lettre sur le Valais» (lettre XXIII) dans La Nouvelle Héloïse: Saint-Preux, ayant parcouru quelques vallées, rêve d'y vivre avec Julie un amour innocent et durable au sein d'une communauté montagnarde et d'une nature aimable. Parmi les théories du paysage, 
celle d'A. Berque apparaît complète et intégrative, car la médiance est un rapport entre l'homme et l'espace naturel dans ses trois dimensions, biophysique, culturelle et subjective.

3 Les gravures aquarellées de Caspar Wolf témoignent d'une ambition picturale et scientifique, le regard maîtrisant l'espace dans lequel le peintre se projette et où la nature construite est identifiable, parlante: «le moi et le paysage agrandissent l'ensemble», comme l'écrit Goethe, dans sa Lettres de Suisse. Dans Les Voyages dans les Alpes de H.B. de Saussure tous les sens interagissent: sur le Cramont - belvédère sur le mont Blanc- il a son fameux «rêve géologique». En 1839, au sommet de Rigi, Hugo pense: «Ces montagnes sont des vagues géantes... On croirait un océan monstrueux figé au milieu d'une tempête par le souffle de Jéhovah» (p. 79). Dans Impressions de voyage en Suisse (1833-37), Dumas témoigne de sa passion pour les gouffres et les chutes, la descente dans l'abîme de Manfred étant une épreuve initiatique, mais aussi une plongée dans sa propre intimité.

4 La société helvétique fondée vers 1760 est également découverte par l'Europe du voyage avec ses rites et ses assemblées politiques (Landsgemeinde). Une description ironique de Curti y voit un «charivari incroyable» et une «parodie de civisme». Le combat pour la démocratie et la liberté nationale trouvent dans Guillaume Tell (1804) un symbole d'efficacité et un centre rayonnant. Mme de Staël décrit en 1808 la fête des bergers, attentive à son érotique et à son «trop visible», introduisant, avec les fantômes du passé, la dimension temporelle. Elle voit dans la fameuse pièce Le Vingt-Quatre Février de Z.Werner un drame de l'enfermement, la pastorale tournée en cauchemar. Max Frisch n'a cessé d'analyser cette insularité helvétique qui s'accroche à sa mythologie alpestre: son Guillaume Tell pour les écoles (1971) est un hypertexte ironique contre l'interprétation romantique des origines.

5 Les descriptions des Alpes, conclut l'auteur, résument l'esprit suisse de ce milieu, avec son sens pratique et son patriotisme, ses institutions et son moralisme protestant. La question des Alpes suisses reste actuelle parce que ce prototype du paysage absolu est menacé par certaines activités humaines: la massification des loisirs et l'industrie alpine remplacent la promenade, introduisant de multiples interactions par la consommation des panoramas en voiture ou en télécabine. 